Journal of Applied Pharmaceutical Science Vol. 5 (09), pp. 143-152, September, 2015

Available online at http://www.japsonline.com

DOI: $10.7324 / J A P S .2015 .50927$

ISSN 2231-3354 (cc) BY-NC-SA

\title{
Carbon Nanotubes: a viable drug delivery platform for the treatment of cancer
}

\author{
Juan Fernando Pinillos-Madrid*, Cecilia Gallardo \\ Department of Pharmacy, University of Antioquia,Calle 67 N 53-108, Medellin, Colombia.
}

\section{ARTICLE INFO \\ Article history: \\ Received on: 21/03/2015 \\ Revised on: 07/04/2015 \\ Accepted on: 09/05/2015 \\ Available online: 27/09/2015}

Key words:

Nanotechnology, carbon

nanotubes, cancer, drug

delivery systems, targeting.

\begin{abstract}
The development of new drug delivery platforms and specific vectorization processes for the treatment of diseases like cancer has become vitally important for the pharmaceutical industry. One of these new platforms are functionalized carbon nanotubes (f-CNTs), which are characterized by their high aspect ratio, high loading capacity, rich surface chemistry with functional groupsfor binding drugs and molecules. It has been demonstrated that functionalization processes of CNTs generate a marked decrease in toxicity, which makes them ideal candidates for clinical studies for their use as drug vectors.
\end{abstract}

\section{INTRODUCTION}

One of the revolutionary fields in nanotechnology is nanomedicine, which is principally based on the exploitation of the nanometric scale for biomedical uses. Nanomedicine focuses on the development of new platforms for the diagnosis and treatment of diseases. It poses two important challenges: (1) understand the effect of drugs from knowledge their interactions with biomedical systems at a molecular level, and (2)control with high precision these effects. The latter of these two challenges requires the development of drug delivery nanometric platforms, also known as nanoplatforms, nanostructures, nanocarriers or nanoparticles. The existing set of nanoparticles so far includes liposomes, smart polymers, dendrimers, viral nanoparticles, metal nanoparticles, polymeric nanoparticles, solid lipid nanocarriers, mesoporous silica nanoparticles, etc. In the figure 1 and figure 2 are shown some nanoplatforms compared to what we know. Liposomes are the platforms most studied and were the first to be accepted for commercialization by the FDA. Two examples are Doxil (doxorubicin $\mathrm{HCl}$ ), commercialized by Ortho Biotech Products, and Vysudine (Verteporfin) from Novartis.

* Corresponding Author

Email: juan.pinillos@udea.edu.co

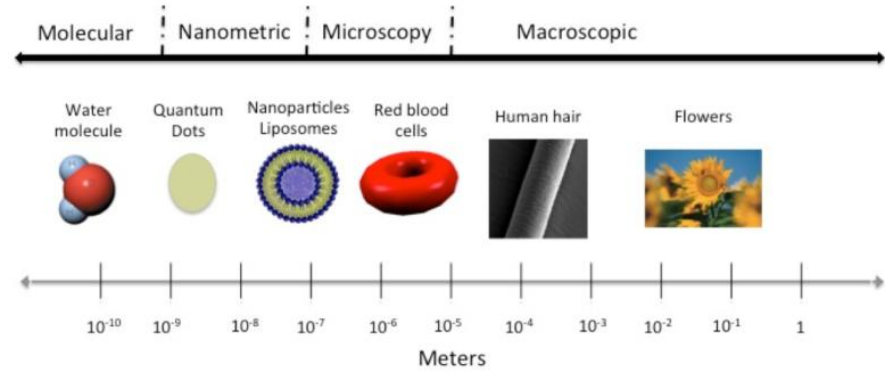

Fig. 1: Scale of the representative sizes know objects.

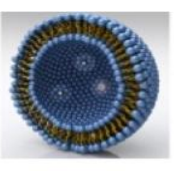

Liposome

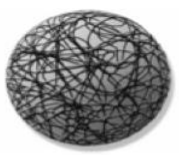

Polymeric nanosphere

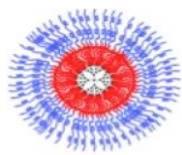

Polymeric micelle

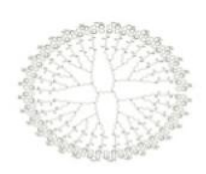

Dendrimers

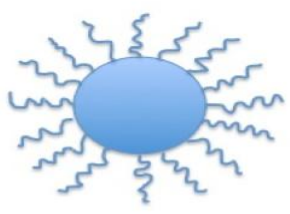

Nanoparticles functionalized with polymers
Fig. 2: Nanoparticles used for drug delivery in biological systems. 
Table 1: Pharmaceutical products commercially availableon a nanometric scale (Zolnik and Sadrieh, 2009).

\begin{tabular}{|c|c|c|c|c|c|}
\hline Drug name & Generic name & Nanoplataform & Company & Indication & $\begin{array}{l}\begin{array}{l}\text { Route of } \\
\text { administrations }\end{array} \\
\end{array}$ \\
\hline Abelcet & Amphotericin B & Liposome & Enzon Pharmaceuticals & Antifungal & i.v. \\
\hline Abraxane or nab-PTX & Paclitaxel & Albumin-bound particles & Abraxis oncology & Cancer & i.v. \\
\hline AmbiSome & Amphotericin B & Liposome & Astellas Pharma US, Inc. & Antifungal & i.v. \\
\hline AmBisome & Amphotericin B & Liposome & Gilead sciences & Antifungal & i.v. \\
\hline Bind-014* & Docetaxel. & Polymeric & Bind Therapeutics & Cancer & i.v. \\
\hline Caelyx & Doxorubicina & Liposome & Schering-Plough, S.A & Cancer & i.v. \\
\hline CALAA- $01 *$ & siRNA & Rondel TM & Calando pharmaceuticals inc & Cancer & i.v. \\
\hline Cynviloq $^{\mathrm{TM}}$ & Paclitaxel & Polymeric micelle & Sorrento Therapeutics & Cancer & i.v.y \\
\hline DaunoXome & $\begin{array}{l}\text { Daunorubicin } \\
\text { citrate }\end{array}$ & Liposome & Diatos & Cancer & i.v. \\
\hline DaunoXome, & Daunorubicin & liposome & Diatos, & Cancer & i.v. \\
\hline Depocyt & Cytarabine & Liposome & Enzon Pharmaceuticals & Lymphomatous meningitis & i.t. \\
\hline Doxil & Doxorubicin $\mathrm{HCl}$ & Liposome & Ortho Biotech Products, LP & Cancer & i.v. \\
\hline Genexol-PM & Paclitacel & Polymeric micelle & $\begin{array}{l}\text { Samyang } \\
\text { Biopharmaceutic }\end{array}$ & cancer & i.v. \\
\hline Invega Sustenna & $\begin{array}{l}\text { Paliperidone } \\
\text { palmitate }\end{array}$ & Nanocrystal & Janssen & Schizophrenia. & IM depot \\
\hline $\begin{array}{l}\text { Lipodox } \\
\text { Lipodox } 50\end{array}$ & Doxorubicin & Liposome & Sun Pharma Global FZE & Cancer & i.v. \\
\hline Lipoplatin+ & Cisplatin & Liposome & Regulon & Cancer & i.v. \\
\hline Myocet & doxorubicina & Lipoosome & Enxon Pharmaceuticals & Cancer & i.v. \\
\hline Neulasta & Pegfilgrastim & Polymeric micelle & AMGEN & neutropenia, & Subcutaneous \\
\hline Oncaspar & Pegaspargase & Polymeric micelle & Enzon Pharmaceuticals & Leukemia & IM or IV \\
\hline Rapamune & Sirolimus & Nanocristal & Wyeth & Immunosuppressant & Oral \\
\hline TriCor & Fenofibrate & Nanocristal & Abbott Laboratoires & $\begin{array}{l}\text { Hypercholesterolemia and } \\
\text { Hypertriglyceridemia }\end{array}$ & Oral \\
\hline Triglide & Fenofibrate & Nanocristal & Sciele Pharma, Inc. & $\begin{array}{l}\text { Hypercholesterolemia and } \\
\text { Hypertriglyceridemia }\end{array}$ & Oral \\
\hline Xeplion & Paliperidone & Nanocrystal & Janssen & schizophrenia. & IM depot \\
\hline
\end{tabular}

+ Clinical phase III, "Clinical phase I.

Other examples of nanoplatforms commercially available are reported in Table 1 . Through the use of nanoplatforms for drug delivery, nanomedicine is getting close to what Paul Ehrlich meant in 1904 when he talked about a "magic bullet", because nanostructures are designed to confer therapeutic specificity, in a process known as drug vectorization.

Therapeutic specificity from the combination of three key elements: 1) a targeting ligand to disease to be counteracted, 2) a drug for the treatment of this disease, and 3)a carrier to deliver this drug in the specific place.

There are various reasons for drugs vectorization. One of these is the existence of drugs that are highly toxic to humans and their use is due to the risk-benefit ratio, such is the case with the majority of anti-cancer drugs. Through the technique of vectorization, adverse effects can be reduced or even completely eliminated by preferential delivering the drug to the site of interest, some examples are the efforts that have been made to reduce the systemic effects of doxorubicin (Lin et al., 2012), morphine (Carvalho et al., 2007), paclitaxel (Fetterly et al., 2008) and cisplatin (Stathopoulos et al., 2006). Another reason is the low bioavailability of many drugs due to their low aqueous solubility, limited absorption and distribution in the body. About $70 \%$ of new drugs exhibit poor aqueous solubility (Kawabata et al., 2011), the vectorization process enable modify the interactions of the drug with water, becoming an insoluble drug in a viable option.

Finally, the costs associated to the development of new medicine (Adams and Brantner, 2006), significantly decrease if therapeutic effectiveness of the drug has already been proven.
Through vectorization processes a new medicine may be created with a new performance profile. Considering that currently there are many drugs whose patent protection has expired or is close to expire (Paul et al., 2010), and the fact that it is getting more and more difficult to discover new drugs, vectorization looks to become an ever more attractive strategy.

\section{CANCER AND NANOPLATFORMS FOR THE DELIVERY OF DRUGS}

\section{Therapeutic specificity}

To achieve design particles with therapeutic specificity is important to understand the biochemistry of the disease process that is going to intervene. In this sense, it must be recognizing that in early stages the carcinogenic tumor passively feeds on the oxygen and nutrients by simple diffusion. When the tumor begins to grow and its size is greater than $2 \mathrm{~mm}^{3}$, a hypoxic state is generated and this triggers a complex process known as angiogenesis. The angiogenesis is the formation of small blood vessels from those that already exist. This process consists of 5 stages: (1) activation of endothelial cells, (2) degradation of the support membrane, (3) migration of cells from the endothelium, (4) vessel formation and (5) angiogenic remodeling (Bergers and Benjamin, 2003).

The knowledge of angiogenesis process has provided two strategies to confer therapeutic specificity to the drug delivery nanostructures: passive and active specificity. The passive specificity, which takes advantage of an effect known as the 
enhanced permeability and retention effect (EPR effect). Active specificity mostly relies on the functionalization of nanostructures with specific ligands for certain receptors that are over-expressed either within the tumor or in the surrounding vascular tissue (Lammers et al., 2012).

\section{Passive specificity}

Passive specificity is based on the exploitation of EPR effect, a phenomenon that is expressed in almost all solid tumors, except in tumors with hypovascularity such as prostate and pancreatic cancer. EPR effect occurs as result of anatomical differences between a neoplastic and a normal tissue. In tumors, aside from the hypervascularization given by angiogenesis, tumor capillaries presents large gaps between the endothelial cells ranging from 100-780 $\mathrm{nm}$, while in normal endothelium is $5-10$ $\mathrm{nm}$, furthermore, solid tumors lack of functional lymphatic drainage (Fang et al., 2011).These factors favor accumulation of the nanostructures in the tumor microenviroment (Nakamura et al., 2014). EPR effect was discovered by Matsumura and Maeda (Matsumura and Maeda, 1986) and has become one of the cornerstones in treatments utilizing drug delivery nanoplatforms. The main problem by this phenomenon is that almost all solid tumors presents a high interstitial fluid pressure, which substantially decreases the uniform distribution of the drug throughout the tumor, especially in its center. Bazak, 2014presents a more complete panorama about passive specificity.

\section{Active specificity}

The active specificity process is based on the binding of ligands to the surface of the nanoparticle. Ligands must be recognized by specific tumor cell receptors or the tumor endothelium. The main characteristic of these receptors is that they must to be uniformly over-expressed in the target cells. The most studied target receptors for carcinogenic cells are transferrin, folate, surface glycoprotein receptors, and the epidermal growth factor receptor (Xu et al., 2013). When a tumor endothelium ligand is used, it is expected that the antineoplastic agent avoid the growth of new blood vessels and promote the death of the existing vessels. In this way, the tumor is killed through the suppression of oxygen and nutrients in its interior. The most studied receptors for tumor endothelium are the vascular endothelial growth factor, the av $\beta 3$ integrin, the vascular cell adhesion molecule-1 (VCAM-1) and matrix metalloproteinases. Wang and Thanou, 2010 give a more extensive analysis of active specificity.

To date, a new generation of nanoparticles is emerging, which looks for targeting at subcellular level, this new challenge arises that the drug is released within specific cellular organelles as the attempts to the selective accumulation in the mitochondria, e.g. it was found that nanoparticles positively charged are preferentially located in mitochondria of human cervical cancer (HeLa) cells (Marrache and Dhar, 2012). Also, it has tried to develop nanoparticles targeted to the nucleus where the endoplasmic reticulum and the Golgi apparatus have been used as vias to reach nucleus (Reilly et al., 2012). A comprehensive review for this new level of complexity of the nanoparticles is presented by Yameen, 2014.

\section{General characteristics of nanoparticles with therapeutic specificity}

Some physical properties of the nanoparticles crucially influence their interaction with biological systems and therefore their performance as drug-carriers. These properties affect the kinetic behavior and intratumoral penetration of the nanoparticles. The nanoparticles to achieve an accumulation process on tumor tissue, must maintaining in the systemic circulation for a long time, and must avoid being excreted from the body quickly or eliminated by the reticule endothelial system (RES). The nanoparticles, after being injected intravenously into the body, are distributed into multiple RES organs, mainly the liver (between $60 \%-90 \%)$, spleen ( $2 \%-10 \%)$, lungs (3\% - 20\%, even more), and bone marrow (1\%) (Gastaldi et al, 2014). The clearance by RES begins with opsonization process, where a foreign particle is covering with non specific proteins to be recognized by phagocytic cells (Owens and Peppas, 2006).

The nanoparticle size affects its ability to reach the tumor and accumulate there. The extravasation to the tumor require that the nanoparticle was smaller than the fenestrations of neovascularization of the tumor $(400-600 \mathrm{~nm})$ (Ernsting et al., 2013). Several studies have shown the degree of influence of nanoparticles size on its penetration in tumor (Huo, 2013; Hrkach et al., 2012). The size also affects the systematic distribution and the clearance of nanoparticles, smaller sizes favor excretion in the kidneys (5.5 nm cut off renal filtration) (Choi et al., 2007) and larger sizes favor metabolism by the liver (50-100 nm cut off liver filtration), or are leakage at the inter-endothelial splenic cell slits(400-500 nm) (Moghimi et al., 1991). Consequently, the size of the drug delivery nanoparticles must be between $10-100 \mathrm{~nm}$.

The surface charge particle is essential to avoid the opsonization process because it has been found that the proteins are adsorbed on the surface of the nanoparticles through electrostatic interactions, hence the neutral particles are less prone to opsonization ( $\mathrm{Li}$ and Huang, 2008), while positive and negative nanoparticles, with zeta potential in the range of $-10<\varsigma$-potential $>10 \mathrm{mV}$ ) are strongly opzonizable (Xiao, 2011). Positive ones exhibits a greater effect. In addition, the nanoparticle charge also influences cellular uptake, since the cell membrane is dominated by a negative environment conferred by the presence of sulphated proteoglycans (Bernfild et al., 1999). In the case of cancer cells, the negative charge density on the cell surface is increased due to the translocation of anionic molecules (such as phosphatidylserine) from the inner layer of membrane to the surface cell (Ran, 2002).Hence the positive nanoparticles are adsorbed on the cell membrane by electrostatic forces, and then they are internalized through pinocytosis, endocytosis or other process. (Löhr et al., 2012). Since nanoparticles charge can promote processes that positively or negatively affect drug targeting delivery, the zeta potential of the nanoparticle must be optimized to enhance the 
intratumoral accumulation of the drug. A major review is presented by Honary and coworker, 2013a and 2013b.

The modification of nanoparticle surface by hydrophilic polymers like polyethylene glycol (PEG), is a strategy extensively used in drug targeting, to prevent the opsonization and protect the nanoparticles from being cleared up by RES and reduce hematological toxicity when they are administrated for i.v. via. PEGylation can amend the pharmacokinetic behavior of nanoparticles because imparts to nanoparticle steric hindrance, a high hydrodynamic size due to capacity to entangle water molecules, and a softness surface (Termsarasab et al., 2014, Rabanel et al., 2014).

The effectiveness of PEGylation rely on long chain and coverage-density, these factors can also avoid nanoparticles reach the target tumor by inhibition of cellular uptake mechanisms or prevent binding with proteins targets (Rabanel et al., 2014, Kim et al., 2013). Recently, it has been observed that PEG-coating results in the generation of PEG specific IgM antibodies that enhance clearance under in vivo assays under repeated administration, effect known as the "accelerated blood clearance (ABC) phenomenon (Abu Lila et al., 2013).

A new approach to improve the circulation time, it is the association of nanoparticles with circulatory cells, where the nanoparticles are attached to cell by adsorption, covalent binding or internalization. This strategy has been coined as cellular hitchhiking-based drug delivery (Anselmo and Mitragotri, 2014).

Another important aspect is the shape, because nanoparticles can take many forms such as spheres, needles, tubes, among others. An inadequate control of the size and shape can affect the toxicological response in the organism in negative way (Ernsting et al., 2013, Toy et al, 2014). It has been observed that nanoparticle geometry is a pivotal factor in the interaction with macrophages, the elongated particles are less prone to internalization via phagocytosis (Mathaes et al., 2014).

\section{CARBON NANOTUBES AS NANOPLATFORMS FOR ANTINEOPLASTIC AGENT DELIVERY}

Carbon nanotubes (CNTs) are an allotropic form of carbon like diamond, graphite and fullerenes. Their structure consists of a layer of graphite wrapped around itself(see Figure 3a). The way the layers are rolled up and the conformation of the original layer result in nanotubes of different diameters and internal geometry. NTCs are classified as simple-walled nanotubes (SWCNT) and multiple-walled nanotubes (MWCNT). CNTs have interesting properties mainly due to a structural conformation that gives them great versatility and potential for use in different applications (Kim et al., 2014) despite the short time that has elapsed since their characterization by the Japanese scientist Iijima in 1991 (Iijima, 1991). They exhibit some features that not favor the biological interaction as their hydrophobic nature, which leads to they are prone to agglomerate and cause cell death (Peretz and Regev, 2012). Therefore the pristine-CNT surface modification is necessary to make them compatible in the biological environment
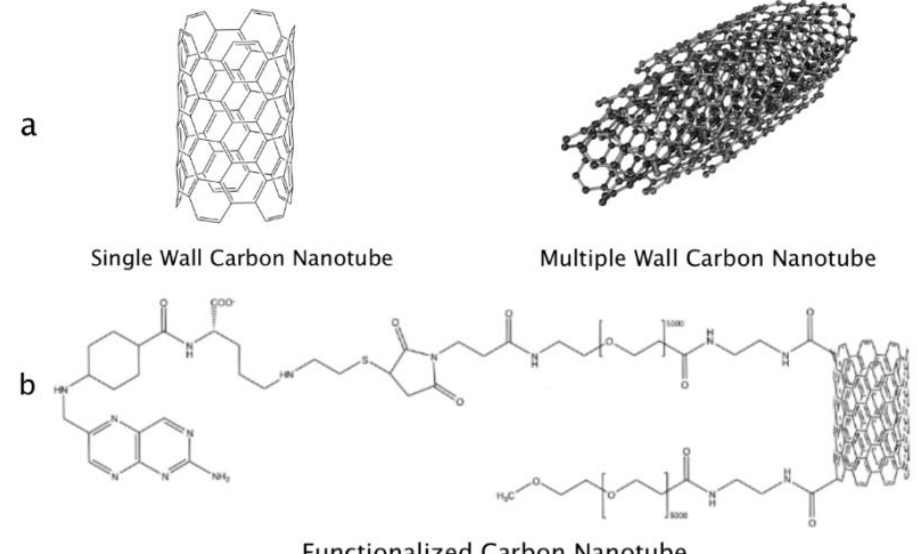

Functionalized Carbon Nanotube

Fig. 3: Simple walled, multiple walled carbon nanotubes and carbon nanotubes functionalized by PEG and Folic Acid by covalented linkage like example of process of fucntionalization.

(Battigelli et al., 2013), resulting a new type of NTC coined as functionalized nanotubes (f-NTC)(see Figure 3b). One of the most interesting applications for f-CNTs is their use in the treatment of diseases in areas as oncology, gene delivery, infectious diseases, and vaccines (Karimi, et al 2015). f-NTCs are currently considered a potential biomedical material to vectorization of drugs due to: (1) their ability to across the cellular membrane via passive diffusion in several types of cells, and also through energetically active routes (Kostarelos et al., 2007, Lacerda et al., 2013),(2) extremely high loading capacity due to ultrahigh surface area up to $2600 \mathrm{~m} 2 / \mathrm{g}$ (Sun et al,2014), and also by their hollow monolithic structure; in fact, they are one of the nanoparticles with larger capacity of drug entrapment (Mody et al., 2014), (3) rich surface chemistry which enables to simultaneously attach a wide range of molecules with different functions in nanomedicine, for example for targeting and imaging. Therefore f-CNTs represent a versatile structure compared with other nanoparticles,(4) f-NTCs exhibit an optical absorption from visible to NIR, allowing their use in photothermal therapy, which complements the chemotherapy (Wang et al., 2013) and (5) f-CNT as any nanoparticles undergo the EPR effect resulting in an intratumoral accumulation.

On the other hand, one of the limitations of nanotubes is related to their toxicity. This will be discussed in the section below.

\section{Toxicological aspects}

Regarding this issue, it is necessary to distinguish the toxicity induced by occupational exposure of pristine-NTC and that induced by intentional administration of f-CNT in nanomedicine. Since the growing number of industrial applications of CNT, there are a significant number of workers who are exposed to handling of them, becoming an important occupational health problem. In these case, the major route of exposure for CNTs is the inhalation, leading to pulmonary accumulation and generating pathologic responses similar to those produced by the asbestos fibers (Stella, 2011): inflammation, fibrosis, oxidative stress, and mutagenesis. This effect has undoubtedly delayed the 
use of f-NTC in nanomedicine. It has been found that the toxicity depends on the physicochemical properties of the CNTs, as size, surface properties and synthesis impurities, and pharmacological parameters (dose, administration via).

Pristine-NTCs exhibit small diameters and great lengths (approximate length up to $1 \mathrm{~mm}$ with diameters between $0.4 \mathrm{~nm}$ up to $100 \mathrm{~nm}$ ). The needle-like shape enables NTC pierce the cell membrane, favors the indiscriminate adsorption by any cell type, facilitates their recognition and accumulation by RES and confers a similar behavior to asbestos fibers (Firme and Bandaru, 2010).Size reduction becomes an important tool to improve the safety profile as the biodistribution of f-NTC. With the advent of new technologies of production of CNT, it is possible to obtain homogeneous diameters, while the length control requires additional processes (Bouanis et al., 2014). Various techniques such as mechanical fracture, selective oxidation and growth control have been implemented to shorten NTCs (Tserpes et al., 2006, Kang et al., 2006, Rauwald et al., 2009). It has found that pristine-NTC $>10 \mu \mathrm{m}$ produce granuloma, pristine-NTC $<10 \mu \mathrm{m}$ are retained by RES, whereas oxidized SWNTC $<300 \mathrm{~nm}$ and oxidized MWCNT $<500 \mathrm{~nm}$ are excreted via the kidneys and bile ducts (Kolosnjaj-Tabi et al., 2010, Jain et al., 2011). The f-NTC diameter also affects its biodistribution, narrow diameters $(9.2 \mathrm{~nm})$ exhibit a higher tissue accumulation than wider diameters (39.5 nm) (Wang, 2014a).

Regarding impurities, transition metals (As, Fe and Ni) are used as primers in the synthesis of NTCs by chemical vapor deposition, remaining bonded to them as impurities, and may represent between $20 \%$ and $40 \%$ of their weight. The metal impurities may act as biocatalysts, thereby promoting the formation of oxidative species and generate cell death by apoptosis (Firme and Bandaru, 2010). Purification processes using strong acids such as $\mathrm{HCl}, \mathrm{H}_{2} \mathrm{SO}_{4}$ and $\mathrm{HNO}_{3}$, which act as oxidizing agents, can remove these metals and other impurities such as carbon graphite and thus can reduce the toxicological effect exerted by themselves. At the moment, there are new synthesis technologies, such as plasma and electric arc to achieve highpurity metallic CNTs, where impurities have been reduced to less than 5\% weight. Pristine-NTCs have highly hydrophobic surfaces, which favors aggregation process resulting in a change in their size and surface area, and in turn increase the citotoxicity (Wick et al, 2007). Functionalization processes are mandatory to impart greater hydrophilicity in the NTC surface. The surface modification can be achieved from two approaches: covalent and non-covalent functionalization.

The non-covalent functionalization consists in the binding of amphiphilic macromolecules to NTC surface through physisorption by $\pi$ - $\pi$ stacking, hydrophobic interactions or macromolecules wrapping (see figure 4). It has been performed numerous studies with various surfactants of different nature (ionic and non-ionic) to evaluate its effect on the dispersibility and adsorption of drugs on NTC (Madni et al., 2010, Oleszczuk and Xing, 2011).

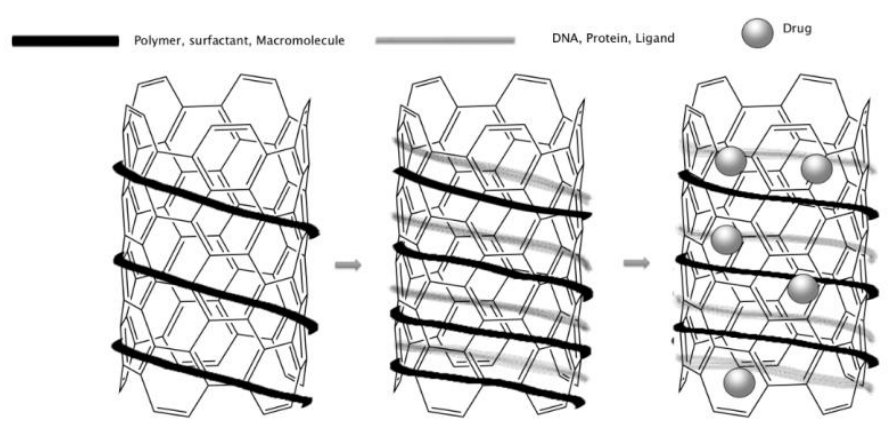

Fig. 4: No-covalent functionalization of Carbon Nanotubes.

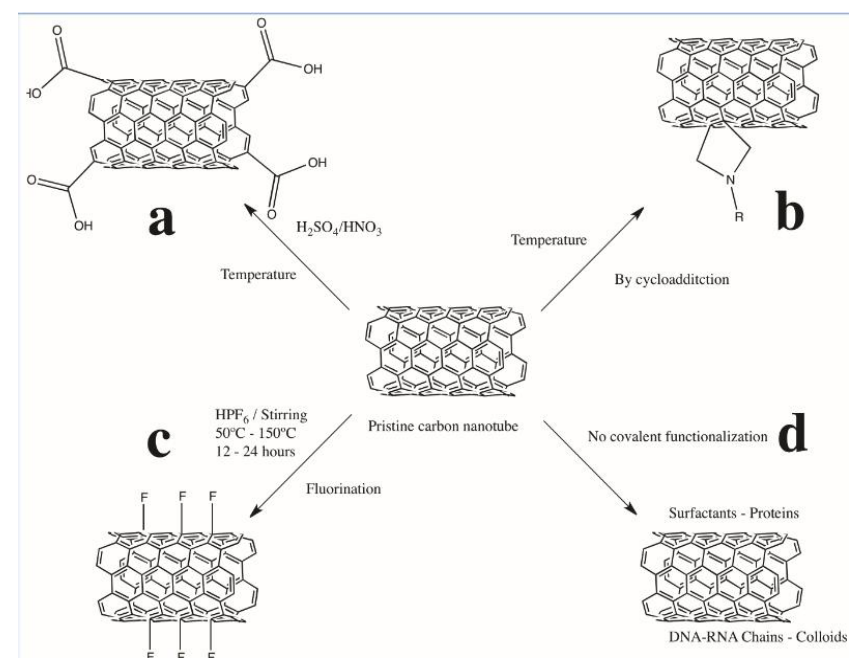

Fig. 5: Functionalization of carbon nanotubes, (a) by oxidation, (b) Cycloaddition, (c) Fluorination, and (d) no covalent functionalization.

Also the non-covalent functionalization has been used in gene therapy to transport proteins, DNA and RNA (Krajcik et al., 2008, Wu et al., 2008, Lee and Mijovic, 2009). However, the main disadvantage of this method is that there are several factors at biological level that can affect the stability of interaction NTCfunctionalizing agent, such as $\mathrm{pH}$, temperature of the body. Another inconvenience of non-covalent functionalization is the toxic effects associate to solvents used to generate CNTs dispersion, such as THF, dichlorobenzene and dimethylsulfoxide, which remain as traces (Madni et al., 2010). Covalent functionalization is based on the binding of the modifier agent by forming of a covalent linkage. There are two subcategories: a direct method where molecules are tethered on NTC sidewall through addition reactions, such as cycloaddition, halogenation, etc (Chehimi, et al 2013), and an indirect method whose initial step is the formation of oxygenated groups on the NTC defect sites such as the opened tips, which act as sites for anchoring an wide range of molecules by amidation or esterification. The generation of active sites (oxygen functional groups such as carboxylic, ketone, alcohol, and ester) is achieved by oxidation with strong acids such as $\mathrm{H}_{2} \mathrm{SO}_{4}$ and $\mathrm{HNO}_{3}$. The oxidation process also leads to shorten CNTs and removes impurities such as amorphous carbon and residual metal (Likodimos et al., 2014). Figure 5 shows some of mechanisms of functionalization of NTCs. 
Table 2: Vectorization of antineoplastic drugsin f-NTC.

\begin{tabular}{|c|c|c|c|c|}
\hline $\begin{array}{l}\text { Antineoplastic } \\
\text { agent }\end{array}$ & NTC Type & Funcionalizant agent/ Ligand & Bioassays; cell line/animal model & Ref \\
\hline Paclitaxel & SWNTC & $\begin{array}{l}\text { Hydroxyl and carboxyl functional } \\
\text { groups }\end{array}$ & $\begin{array}{l}\text { MCF-7 and SK-BR-3 breast cancer } \\
\text { cells/Nude mice }\end{array}$ & Wang et al ., 2014 \\
\hline Gliotoxin & SWCNT & $\begin{array}{l}\text { Chitooligosaccharide/ Lysozyme, p53 } \\
\text { and Folic acid }\end{array}$ & $\begin{array}{l}\text { cervical cancer (HeLa) cells and Breast } \\
\text { Cancer (MCF-7) cells/No in vivo assays. }\end{array}$ & Bhatnagar et al., 2014 \\
\hline Doxorubicin & MWCN & $\begin{array}{l}\text { d- } \alpha \text {-tocopheryl polyethylene glycol } \\
1000 \text { succinate }\end{array}$ & $\mathrm{MCF}-7$ cell/Balb/c mice & Mehra et al., 2014 \\
\hline Doxorubicin & SWCNT & Chitosan/Hyaluronan & HeLa cells and fibroblasts. Not in vivo & Mo et al., 2015 \\
\hline Doxorubicin & Iron- SWCNT & $\begin{array}{l}\text { PVP/Endoglin/CD105 } \\
\text { antibodies }\end{array}$ & T1-Luc2 cancerous cells/ Balbc mice & Al Faraj, et al., 2015 \\
\hline Cisplatin & SWCNT & phospholipids & $\begin{array}{l}\text { C26 colon carcinoma cells and in vivo in } \\
\text { BALB/c mice }\end{array}$ & Kazemi-Beydokhti, et al., 2014, \\
\hline
\end{tabular}

The mere fact of introducing oxygen functional groups in the NTC surface can improve the biocompatibility. It has been observed oxidized MWNTC (<500 nm) inducing minimal hepatic accumulation and inflammation response after a single administration, because they are more easily cleared from the body via renal excretion, compared with pristine-MWNTC, which are retained in lungs and liver (Jain et al., 2011). The cytotoxicity of oxidized MWCNTs decreases as a function of functionalization density according studies in vitro using macrophages (Singh et al., 2012). A growing body of literature indicates that if the nature of the functionalizing agent favors the aqueous dispersion without forming tangling/bundling of CNTs, it can be expected that f-NTC not lead to an inflammatory response in vivo studies (Ali-Boucetta et al., 2013). In this same line of reasoning, it has been found that increasing the degree of functionalization improves the cytotoxic profile, because the f-NTCs interact with biological system as individualized nanoparticle, leading to the rapid urinary excretion and low tissue retention (Al-Jamal et al., 2012). One of the functionalizing agent most used is PEG, due toits high biocompatibility and versatility to bind ligands, drugs and other molecules, among other reasons as mentioned above. It has observed that chain length, coverage-density, conformation adopted by PEG affect the adsorption of corona protein and the activation of the complement system, varying the biological stealth and blood circulation times of f-NTC(Sacchetti et al., 2013).fNTC are facing the same obstacles that other vectors in nanomedicine, because it is recognized that there is not still enough research to know the complexity of the complement system (Farrera et al., 2015), and to achieve design nanoparticles with high biological stealth and low RES clearance. Table 2 shows some studies of f-NTC as anticancer drug delivery system, reported during 2014. Different type of agents and ligands are been evaluated both biological compatibility and antitumor efficacy by in vitro and in vivo studies.

\section{Biodegradation de NTC}

A recent focus of research is the biotransformation of NTCs. Studies in vitro have shown the biodegradation of the oxidized-NTC by peroxidase enzymes such as horseradich peroxidase (HRP), human myeloperoxidase (MPO) and eosinophil peroxidase (EPO) under the presence of low concentration of $\mathrm{H}_{2} \mathrm{O}_{2}$ and generating $\mathrm{CO}_{2}$ as final product (Russier et al., 2011;
Zhao et al., 2011,Andon et al, 2013, Kotchey et al., 2013, Kagan et al., 2010). The degradation of carboxilated MWNTC is a slower process that SWCNT and occurs layer-by-layer (Zhao et al., 2011) (see figure 6).

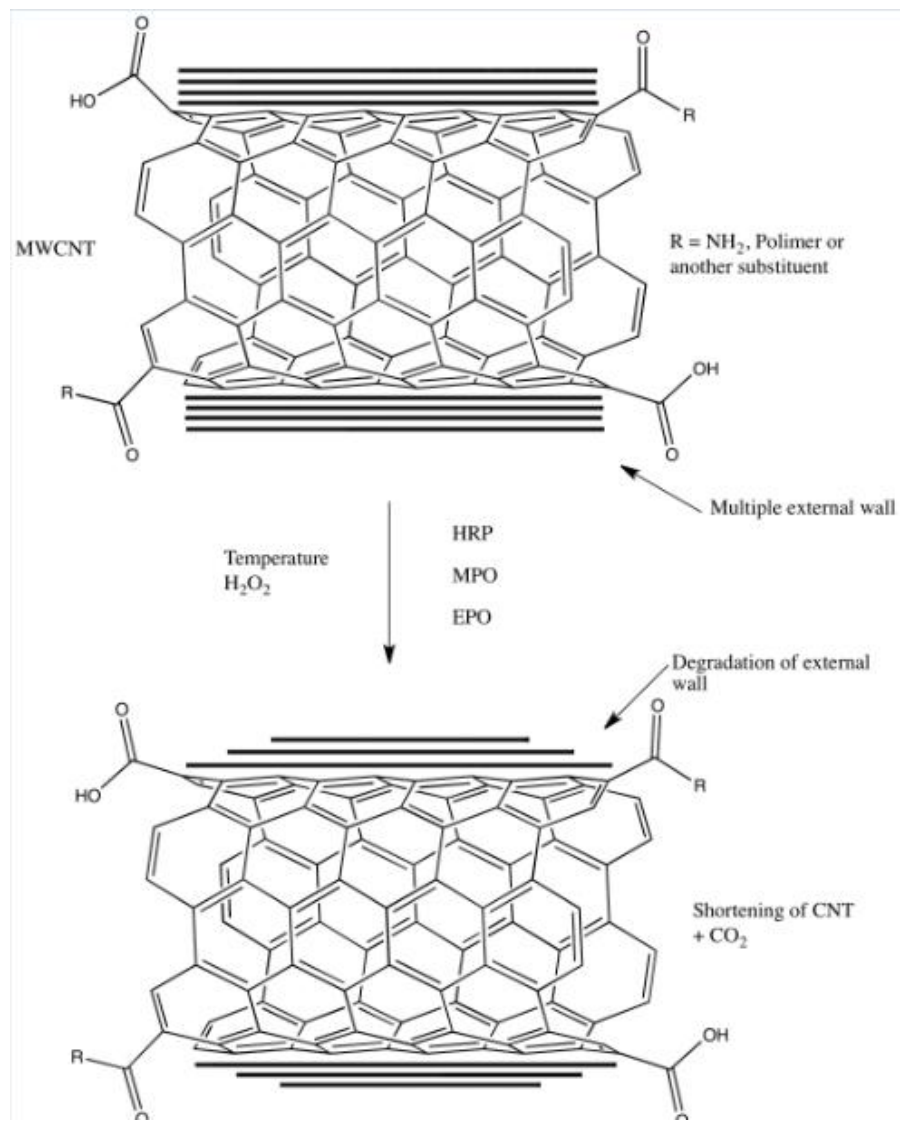

Fig. 6: General scheme of functionalized carbon nanotubes biodegradation process.

The fact that this result is observed in the oxidized-NTC, is attributed to carboxylate groups facilitate the orientation of NTC near the heme site of peroxidases (Allen et al., 2009, Kagan et al., 2010). The proposed mechanism also involve a role of $\mathrm{Cl}^{-}$, which is became into hypochlorous acid $(\mathrm{HClO})$ by MPO and EPO. $\mathrm{HClO}$ synergizes the oxidizing ability of these enzimes (Vlasova et al., 2011). Studies at level cellular and in vivo, demonstrated that MPO (enzyme present in neutrophils) and EPO (in 
eosinophils) in addition to its bactericidal function, protection against parasites and ability to oxidatively modify organic xenobiotics, are able to oxidatively degrade NTCs (Andón et al., 2013, Vlasova et al., 2012, Shvedova et al., 2012; Shvedova et al., 2012).

These results indicate that exists an alternative pathway (different from urinary or fecal excretion) to remove short and oxidized-NTCs and prevent their accumulation in organs such as lungs (see figure 7). The outcomeof in vitro studies have been controversial by a recent study, where it is demonstrated by different analytical methods that HRP degradation of different types of NTCsis slow, with half-lives of 80 years (FloresCervantes et al., 2014). This has encouraged other researchers since the NTC biotransformation has large impacts on both environmental and human health. Recent studies have reported of biodegradation of SWNTC by superoxide/peroxynitrite oxidative pathway of activated macrophages (Kagan. 2014) and manganese peroxidase (Zhang et al., 2014)

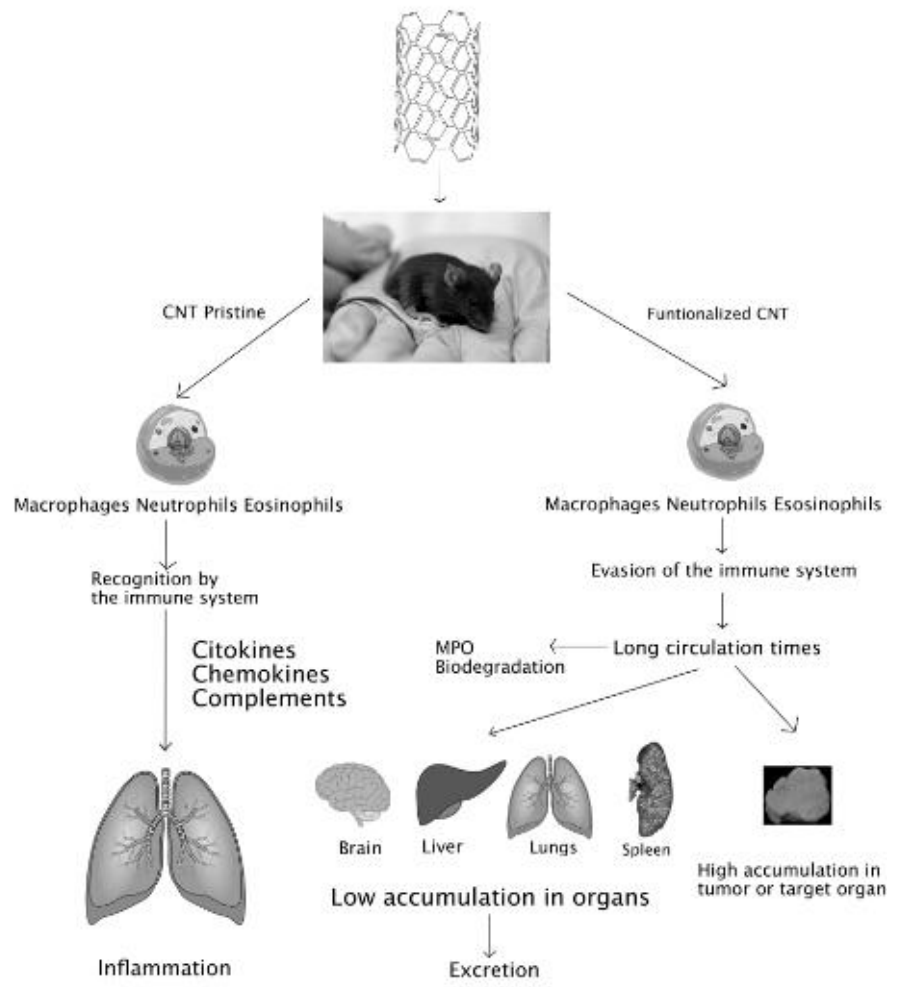

Fig. 7: Path follows the pristine and functionalized CNT in the body.

\section{Drug vectorization in nanotubes}

The binding of the drug to the f-NTC is accomplished with the same methods used to tether functionalizing agents on NTC surface, i.e. by covalent bond or physisorption.

Drug vectorization by covalent bond is achieved using spacer agents as ethylenediamine, cisteamine, diaminotriethylene glycol, etc to link the drug directly to the NTC (Wu et al., 2009, Bhirde et al., 2009, Samori 2010), or the drug can be link to functionalizing agent by esterification (Chen et al., 2012, Marega et al., 2011).
The vectorization by physisorptionis the most used because ithas two advantages, the first one is that the structure of the drug does not change and the second one is that the capacity of load of NTC is fully taken advantage. Various studies have been carried out indicating that there are a variety of possible forms in which drugs can be encapsulated, such as within the inner cavity of f-NTCs (Muzi et al., 2015), or hydrophobic interactions, hydrogen bridges and $\pi-\pi$ interactions on f-NTC surface (Mehra et al., 2014, Li et al., 2011).An approach to understanding these interactions is achieved through adsorption isotherms, such as isotherms of Langmuir, Freundlich, Sips and Polanyi-Manes Model.

\section{CONCLUSIONS}

NTCs present several properties that make them one of vectors more appropriate for use in chemotherapy, such as: high capacity, needle-like shape and versatile surface to attach different molecules.

It has been observed that the inflammatory response and cell death caused by the NTCs are related to their size, metal impurities and tendency to form agglomerates. Short f-NTCs show a different behavior than pristine-CNTs, the former are less retained by RES organ, are more rapidly removed by the renal excretion and are biodegraded. Therefore the functionalization of NTC has generated great expectations in nanomedicine. However, because the studies so far have high disparity between the characteristics of f-NTCs used and the conditions of the experiment, is not exactly known how the functionalization affects the kinetics that follow the f-CNTsat biological level and the biodistribution.

Also, it is necessary to overcome difficulties associated with interactions between f-NTCs and immune system, to achieve modular blood circulation time and promote the accumulation in target organ.

NTC biotransformation is a recent field of research and more experimental evidences are needed to reach a consensus on the metabolic pathways involved as the kinetics of biodegradation, using appropriate methods.

\section{ACKNOWLEDGEMENTS}

The authors would like to thank COLCIENCIAS for financial support.

\section{REFERENCES}

Abu Lila AS, Kiwada H, Ishida T. The accelerated blood clearance $(\mathrm{ABC})$ phenomenon: clinical challenge and approaches to manage. J. Control. Release, 2013; 172: 38-47

Adams CP, Brantner VV. Estimating The Cost Of New Drug Development: Is It Really \$802 Million?. Health Affairs, 2006; 25(2):420428.

Al Faraj A, Shaik AP, Shaik AS. Magnetic single-walled carbon nanotubes as efficient drug delivery nanocarriers in breast cancer murine model: noninvasive monitoring using diffusion-weighted magnetic 
resonance imaging as sensitive imaging biomarker. International journal of nanomedicine, 2015;10:157-168.

Ali-Boucetta H, Nunes A, Sainz R, Herrero MA, Tian B., Prato M,Bianco A, Kostarelos K. Asbestos-like Pathogenicity of Long Carbon Nanotubes Alleviated by Chemical Functionalization. Angewandte Chemie International Edition, 2013; 52(8): 2274-2278.

Al-Jamal KT, Nunes A, Methven L, Ali-Boucetta H, Shouping L, Toma F, Herrero MA, Al-Jamal1 WT, Eikelder HMM, Foster J, Mather S, Prato M,Bianco A, Kostarelos K. Degree of chemical functionalization of carbon nanotubes determine tissue distribution and excretion profile. Angewandte Chemie-International Edition, 2013; 51(26): 63896393.

Allen BL, Kotchey GP, Chen Y, Yanamala NVK, KleinSeetharaman J, KaganVE, Star A. Mechanistic investigations of horseradish peroxidase-catalyzed degradation of single-walled carbon nanotubes. J. Am. Chem. Soc, 2009; 131:17194-17205.

Andón FT, Kapralov AA, Yanamala N, Feng W, Baygan A, Chambers BJ, Hultenby K, Ye F, Toprak MS, Brandner BD, Fornara A, Klein-Seetharaman J, Kotchey GP, Star A, Shvedova AA, Fadeel B,. Kagan VE. Biodegradation of single-walled carbon nanotubes by eosinophil peroxidase. Small, 2013: 9(16): 2721-2729.

Anselmo AC, Mitragotri S. Cell-mediated delivery of nanoparticles: Taking advantage of circulatory cells to target nanoparticles. Journal of Controlled Release, 2014;190(0):531-41.

Battigelli A, Ménard-Moyon C, Da Ros T, Prato M, Bianco A. Endowing carbon nanotubes with biological and biomedical properties by chemical modifications. Advanced Drug Delivery Reviews, 2013; 65(15): 1899-920.

Bazak R, Houri M, El Achy S, Hussein W, Refaat T. Passive targeting of nanoparticles to cancer: A comprehensive review of the literature.Molecular and Clinical Oncology, 2014;2(6): 904-908.

Bergers G, Benjamin LE. Tumorigenesis and the angiogenic switch. Nat Rev Cancer, 2003;3(6):401-10.

Bernfild M, Gotte M, Park PW, Reizes O, Fitzgerald ML, Lincecum J, Zako M. Functions of cell surface heparan sulphate proteoglycans. Annu. Rev. Biochem, 1999; 68: 729-777.

Bhatnagar I, Venkatesan J, Kim, SK. Polymer functionalized single walled carbon nanotubes mediated drug delivery of gliotoxin in cancer cells. Journal of biomedical nanotechnology, 2014;10(1): 120-130.

Bhirde AA, Sousa AA, Patel V, Azari AA, Gutkind JS, Leapman RD, Rusling JF. Imaging the distribution of individual platinumbased anticancer drug molecules attached to single-wall carbon nanotubes. Nanomedicine, 2009; 4:763-772.

Bouanis FZ, Cojocaru CS, Huc V, Norman E, Chaigneau M, Maurice JL,Mallah T, Priba D. Direct Synthesis and Integration of Individual, Diameter-Controlled Single-Walled Nanotubes (SWNTs). Chemistry of Materials, 2014; 26(17):5074-5082.

Carvalho B, Roland LM., Chu LF, Campitelli VA, Riley ET. Single-dose, extended-release epidural morphine (DepoDur) compared to conventional epidural morphine for post-cesarean pain. Anesth Analg, 2007;105:176-183.

Chehimi M M, Pinson J, Salmi Z. 2013. Carbon Nanotubes: Surface Modification and Applications. In: Chehimi MM, and Pinson J. ed. Applied Surface Chemistry of Nanomaterials: Chemistry Research and Applications. New York: Nova Science Pub Inc,95-144.

Chen G, He Y, Wu X, Zhang Y, Luo C, Jing P. In vitro and in vivo studies of pirarubicin-loaded SWNT for the treatment of bladder cancer, Braz. J. Med. Biol. Res, 2012;45: 771-776.

Choi SH, Liu W, Misra P, Tanaka E, Zimmer JP, Itty Ipe BI, Bawend MG, Frangioni JV. Renal clearance of quantum dots. Nat Biotech. 2007;25(10):1165-1170.

Ernsting MJ, Murakami M, Roy A, Li S-D. Factors controlling the pharmacokinetics, biodistribution and intratumoral penetration of nanoparticles. Journal of Controlled Release, 2013;172(3):782-94.

Fang J, Nakamura H, Maeda H. The EPR effect: unique features of tumor blood vessels for drug delivery, factors involved, and limitations and augmentation of the effect Adv. Drug Deliv Rev, 2011; 63 (3):136151
Farrera C, Fadeel B. It takes two to tango: understanding the interactions between engineered nanomaterials and the immune system. European Journal of Pharmaceutics and Biopharmaceutics, 2015, in press.

Fetterly GJ, Grasela TH, Sherman JW, Jeanne L. Dul JL, Grahn A, Lecomte D, Fiedler-Kelly J,Damjanov N, Fishman M, . Kane MP, Rubin EH, Tan AR. . Pharmacokinetic/pharmacodynamic modeling and simulation of neutropenia during phase I development of liposomeentrapped paclitaxel. Clin Cancer Res, 2008; 14: 5856-5863.

Firme CP, Bandaru PR. Toxicity issues in the application of carbon nanotubes to biological systems. Nanomedicine: nanotechnology, biology, and medicine, 2010; 6(2):245-56.

Flores-Cervantes D X, Maes H M, Schäffer A, Hollender J, Kohler HPE. Slow biotransformation of carbon nanotubes by horseradish peroxidase. Environmental science \& technology,2014; 48(9): 4826-4834.

Gastaldi L, Battaglia L, Peira E, Chirio D, Muntoni E, Solazzi I, Gallarate M, Dosio F.. Solid lipid nanoparticles as vehicles of drugs to the brain: Current state of the art. European Journal of Pharmaceutics and Biopharmaceutics. 2014;87(3):433-44.

Honary S, Zahir F. Effect of Zeta Potential on the Properties of Nano-Drug Delivery Systems-A Review (Part1). Tropical Journal of Pharmaceutical Research, 2013a;12(2):255-264.

Honary S, Zahir F. Effect of Zeta Potential on the Properties of Nano-Drug Delivery Systems-A Review (Part 2). Tropical Journal of Pharmaceutical Research, 2013b;12(2): 265-273.

Hrkach J, Von Hoff D, Ali MM, Andrianova E, Auer J, Campbell T, De Witt D, Figa M., Figueiredo M, Horhota A, Low S, McDonnell K, Peeke E, Retnarajan B, Sabnis A, Schnipper E, Song JJ, Song YH, Summa J, Tompsett D, Troiano G, Van Geen Hoven T, Wright J, Lorusso P, Kantoff PW, Bander NH, Sweeney C, Farokhzad OC, Langer R, Zale S. Preclinical development and clinical translation of a PSMA-targeted docetaxel nanoparticle with a differentiated pharmacological profile. Sci. Transl. Med, 2012;4(128): 128- 139.

Huo S, Ma H, Huang K, Liu J, Wei T, Jin S, Zhang J, He S, Liang XJ. Superior penetration and retention behavior of $50 \mathrm{~nm}$ gold nanoparticles in tumors, Cancer Res, 2013;73:319-330.

Iijima S. Helical microtubules of graphitic carbon. Nature, $1991 ; 354: 56-58$

Jain S, Thakare VS, Das M, Godugu C, Jain AK, Mathur R, et al., Toxicity of Multiwalled Carbon Nanotubes with End Defects Critically Depends on Their Functionalization Density. Chemical Research in Toxicology, 2011; 24(11):2028-2039.

Kagan VE, Kapralov AA, St. Croix CM, Watkins SC, Kisin ER, Kotchey GP, BalasubramanianK, Vlasova II, Yu J, Kim K, Seo W, Mallampalli RK , StarA, hvedova, AA. Lung macrophages "digest" carbon nanotubes using a superoxide/peroxynitrite oxidative pathway. ACS nano, 2014; 8(6): 5610-5621.

Kagan VE, Konduru NV, FengW, Allen BL, Volkov CJ, Vlasova II, Belikova NA, Yanamala N, Kapralov A, Tyurina YY, Shi J, Kisin ER, Murray AS, Franks J, Stolz D, Gou P, Klein-Seetharaman J, Fadeel B, Star A, Shvedova AA. Carbon nanotubes degraded by neutrophil myeloperoxidase induce less pulmonary inflammation. Nature nanotechnology, 2010; 5(5): 354-359.

Kang Z, Wang E, Mao B, Su Z, Tian C, Xu L. Controlled cutting carbon nanotube with polyoxometalates assisted renewable method. Materials Letters, 2006; 60(17-18):2266-2269.

Karimi M, Solati N, Ghasemi A, Estiar MA, Hashemkhani M, Kiani P,Mohamed E, Saeidi A, Taheri M, Avci P, Aref AR, Amiri M, Baniasadi F, Hamblin, M. R. Carbon nanotubes part II: a remarkable carrier for drug and gene delivery. Expert Opinion on Drug Delivery, 2015; (0): 1-17.

Kawabata Y, Wada K, Nakatani M, Yamada S, Onoue S. Formulation design for poorly water-soluble drugs based on biopharmaceutics classification system: Basic approaches and practical applications. International Journal of Pharmaceutics. 2011;420(1):1-10.

Kazemi-Beydokhti A, Heris SZ, Jaafari MR, NikoofalSahlabadi S, Tafaghodi M, Hatamipoor M. Microwave functionalized single-walled carbon nanotube as nanocarrier for the delivery of anticancer drug cisplatin: in vitro and in vivo evaluation. Journal of Drug Delivery 
Science and Technology, 2014;24(6): 572-578.

Kim ST, Saha K, Kim C,Rotello VM. The role of surface functionality in determining nanoparticle cytotoxicity. Accounts of chemical research, 2013; 46(3): 681-691.

Kim YA, Yang KS, Muramatsu H, Hayashi T, Endo M, Terrones M, Dresselhaus MS. Double-walled carbon nanotubes: synthesis, structural characterization, and application. Carbon Lett, 2014;15:77-88.

Kolosnjaj-Tabi J, Hartman KB, Boudjemaa S, Ananta JS, Morgant G, Szwarc H, Wilson LJ, Moussa F. In vivo behavior of large doses of ultrashort and full-length single-walled carbon nanotubes after oral and intraperitoneal administration to Swiss mice. Acs Nano, 2010: 4(3):1481-1492.

Kostarelos K, LacerdaL, Pastorin G, Wu W, Wieckowski S, Luangsivilay J, Godefroy S, Pantarotto D, Briand JP, Muller S, Prato M, Biaco A. Cellular uptake of functionalized carbon nanotubes is independent of functional group and cell type. Nature nanotechnology, 2007; 2(2): 108-113.

Kotchey GP, Zhao Y, Kagan VE, Star A. Peroxidase-mediated biodegradation of carbon nanotubes in vitro and in vivo. Advanced Drug Delivery Reviews, 2013; 65(15):1921-32.

Krajcik R, Jung A, Hirsch A, Neuhuber W, Zolk O. Functionalization of carbon nanotubes enables non-covalent binding and intracellular delivery of small interfering RNA for efficient knock-down of genes. Biochem Bioph Res Co, 2008; 369(2):595-602.

Lacerda L, Ali-Boucetta H, Kraszewski S, Tarek M, Prato M, Ramseyer C, Kostarelos K, Bianco A.How do functionalized carbon nanotubes land on, bind to and pierce through model and plasma membranes. Nanoscale, 2013;5(21): 10242-10250.

Lammers T, Kiessling F, Hennink WE, Storm G. Drug targeting to tumors: principles, pitfalls and (pre-) clinical progress. Journal of controlled release, 2012;161(2):175-187.

Lee H, Mijovic J. Bio-nano complexes: DNA/surfactant/singlewalled carbon nanotube interactions in electric field. Polymer, 2009; 50(3): 881-90.

Li R, Wu Ra, Zhao L, Hu Z, Guo S, Pan X, et al., Folate and iron difunctionalized multiwall carbon nanotubes as dual-targeted drug nanocarrier to cancer cells. Carbon, 2011;49(5):1797-805.

LiSD, Huang L. Pharmacokinetics and biodistribution of nanoparticles. Molecular pharmaceutics, 2008;5(4): 496-504.

Likodimos V, Steriotis TA, Papageorgiou SK, Romanos GE, Marques RRN, Rocha RP, et al., Controlled surface functionalization of multiwall carbon nanotubes by $\mathrm{HNO} 3$ hydrothermal oxidation. Carbon, 2014;69(0):311-26.

Lin J, Yu Y, Shigdar S, Fang DZ, Du JR, Wei MQ, Danks A, Liu K, Duan W. Enhanced Antitumor Efficacy and Reduced Systemic Toxicity of Sulfatide-Containing Nanoliposomal Doxorubicin in a Xenograft Model of Colorectal Cancer. PLoS ONE, 2012;7(11): e49277.

Löhr JM, Haas SL, Bechstein WO, Bodoky G, Cwiertka K, Fischbach W, Fölsch UR, Jäger D, Osinsky D, Prausova J, Schmidt WE, Lutz, MP. Cationic liposomal paclitaxel plus gemcitabine or gemcitabine alone in patients with advanced pancreatic cancer: a randomized controlled phase II trial. Annals of oncology, 2012;23(5):1214-1222.

Madni I, Hwang C-Y, Park S-D, Choa Y-H, Kim H-T. Mixed surfactant system for stable suspension of multiwalled carbon nanotubes. Colloids and Surfaces A: Physicochemical and Engineering Aspect,. 2010;358(1-3):101-7.

Marega R, Bergamin M, Aroulmoji V, Dinon F, Prato M, Murano E. Hyaluronan-carbon nanotube derivatives: Synthesis, conjugation with model drugs, and dosy $\mathrm{nmr}$ characterization. European Journal of Organic Chemistry, 2011;(28): 5617-5625.

Marrache S, Dhar S. Engineering of blended nanoparticle platform for delivery of mitochondria-acting therapeutics.Proceedings of the National Academy of Sciences, 2012;109: 16288-16293.

Mathaes R, Winter G, Besheer A, Engert J. Influence of particle geometry and PEGylation on phagocytosis of particulate carriers. International Journal of Pharmaceutics, 2014;465(1): 159-164.

Matsumura Y, Maeda H. A New Concept for Macromolecular Therapeutics in Cancer Chemotherapy: Mechanism of Tumoritropic
Accumulation of Proteins and the Antitumor Agent Smancs. Cancer Research, 1986;46(12 Part 1):6387-92.

Mehra NK, Verma AK, Mishra PR, Jain NK. The cancer targeting potential of $\mathrm{D}$ - $\alpha$-tocopheryl polyethylene glycol 1000 succinate tethered multi walled carbon nanotubes. Biomaterials, 2014;35(15): 45734588 .

Mo Y, Wang H, Liu J, Lan Y, Guo R, Zhang Y, Zue W, Zhang Y. Controlled release and targeted delivery to cancer cells of doxorubicin from polysaccharide-functionalised single-walled carbon nanotubes. Journal of Materials Chemistry B, 2015;3:1846-1855.

Mody N, Tekade RK, Mehra NK, Chopdey P, Jain NK. Dendrimer, Liposomes, Carbon Nanotubes and PLGA Nanoparticles: One Platform Assessment of Drug Delivery Potential. AAPS PharmSciTech, 2014; 15(2):388-399.

Moghimi SM, Porter CJH, Muir IS, Illum L, Davis SS. Nonphagocytic uptake of intravenously injected microspheres in rat spleen: Influence of particle size and hydrophilic coating. Biochem Bioph Res Co, 1991; 177(2):861-866.

Muzi L, Ménard-Moyon C, Russier J, Li J, Chin CF, Ang WH, Pastorin G, Risuleo G, Bianco, A. Diameter-dependent release of a cisplatin pro-drug from small and large functionalized carbon nanotubes. Nanoscale, 2015;7: 5383-5394.

Nakamura H, Etrych T, Chytil P, Ohkubo M, Fang J, Ulbrich K, Maeda H. Two step mechanisms of tumor selective delivery of $\langle\mathrm{i}\rangle \mathrm{N}\langle/ \mathrm{i}\rangle$ (2-hydroxypropyl) methacrylamide copolymer conjugated with pirarubicin via an acid-cleavable linkage. Journal of Controlled Release, 2014;174, 81-87.

Oleszczuk P, Xing B. Influence of anionic, cationic and nonionic surfactants on adsorption and desorption of oxytetracycline by ultrasonically treated and non-treated multiwalled carbon nanotubes. Chemosphere, 2011; 85(8):1312-7.

Owens DE, Peppas NA. Opsonization, biodistribution, and pharmacokinetics of polymeric nanoparticles. International Journal of Pharmaceutics, 2006;307(1): 93-102.

Paul SM, Mytelka DS, Dunwiddie CT, Persinger CC, Munos $\mathrm{BH}$, Lindborg SR, Schacht AL. How to improve R\&D productivity: the pharmaceutical industry's grand challenge. Nature reviews Drug discovery, 2010;9(3): 203-214.

Peretz S, Regev O. Carbon nanotubes as nanocarriers in medicine. Current Opinion in Colloid \& Interface Science,2012;17(6) 360-368

Rabanel JM, Hildgen P, Banquy X. Assessment of PEG on polymeric particles surface, a key step in drug carrier translation. Journal of Controlled Release, 2014;185: 71-87.

Ran S, Downes A, Thorpe PE. Increased exposure of anionic phospholipids on the surface of tumor blood vessels. Cancer Res, 2002; 62: 6132-6140.

Rauwald U, Shaver J, Klosterman DA, Chen Z, Silvera-Batista C, Schmidt HK, et al., Electron-induced cutting of single-walled carbon nanotubes. Carbon. 2009;47(1):178-85.

Reilly MJ, Larsen JD, Sullivan MO. Polyplexes traffic through caveolae to the Golgi and endoplasmic reticulum en route to the nucleus. Molecular pharmaceutics, 2012; 9(5):1280-1290.

Russier J, Ménard-Moyon C, Venturelli E, Gravel E, Marcolongo G., Meneghetti M, Doris E, Bianco A. Oxidative biodegradation of single-and multi-walled carbon nanotubes. Nanoscale, 2011;3(3): 893-896.

Sacchetti C, Motamedchaboki K, Magrini A, Palmieri G, Mattei, Bernardini S, Rosato N, Bottini N, Bottini,M. Surface polyethylene glycol conformation influences the protein corona of polyethylene glycol-modified single-walled carbon nanotubes: potential implications on biological performance. Acs Nano, 2013;7(3):1974-1989.

Samorì C, Ali-Boucetta H, Sainz R, Guo C, Toma FM, Fabbro C, RosT, Prato M, Kostarelos K, Bianco, A. Enhanced anticancer activity of multi-walled carbon nanotube-methotrexate conjugates using cleavable linkers. Chemical Communications, 2010; 46(9): 1494-1496.

Shvedova AA, Kapralov AA, Feng WH, Kisin ER, Murray AR, Mercer RR, St. Croix CM,. Lang MA,Watkins SC,Konduru NV,. Allen 
BL,Conroy J,Kotchey GP,KaganVE.Impaired Clearance and Enhanced Pulmonary Inflammatory/Fibrotic Response to Carbon Nanotubes in Myeloperoxidase-Deficient Mice. PLoS ONE, 2012;7(3):e30923.

Singh RP, Das M, Thakare V, Jain S. Functionalization Density Dependent Toxicity of Oxidized Multiwalled Carbon Nanotubes in a Murine Macrophage Cell Line. Chemical Research in Toxicology, 2012;25(10):2127-37.

Stathopoulos GP, Boulikas T, Vougiouka M, Deliconstantinos G, Rigatos S, Darli E, Viliotou V, Stathopoulos JG. Pharmacokinetics and adverse reactions of a new liposomal cisplatin (Lipoplatin): phase I study. Oncology reports, 2005;13(4):589-595.

Stella GM, Carbon nanotubes and pleural damage: perspectives of nanosafety in the light of asbestos experience. Biointerphases, 2011: 6(2):1-17

Sun H, She P, Lu G, Xu K, Zhang W, Liu Z. Recent advances in the development of functionalized carbon nanotubes: a versatile vector for drug delivery. Journal of Materials Science.2014;49(20):6845-6854.

Termsarasab U, Yoon I-S, Park J-H, Moon HT, Cho H-J, Kim D-D. Polyethylene glycol-modified arachidyl chitosan-based nanoparticles for prolonged blood circulation of doxorubicin. International Journal of Pharmaceutics, 2014; 464(1-2):127-34.

Toy R, Peiris PM, GhaghadaKB, Karathanasis E. Shaping cancer nanomedicine: the effect of particle shape on the in vivojourney of nanoparticles. Nanomedicine, 2014;9(1):121-134.

Tserpes KI, Papanikos P, Tsirkas SA. A progressive fracture model for carbon nanotubes. Composites Part B: Engineering, 2006;37(78):662-9.

Vlasova II, Vakhrusheva TV, Sokolov AV, Kostevich VA, Gusev AA, Gusev SA, Gusev SA, Viktoriya I. Melnikova VI,Anatolii S, LobachAS. PEGylated single-walled carbon nanotubes activate neutrophils to increase production of hypochlorous acid, the oxidant capable of degrading nanotubes. Toxicology and Applied Pharmacology, 2012;264(1):131-42.

Vlasova, I. I., Sokolov, A. V., Chekanov, A. V., Kostevich, V. A., Vasilyev, V. B. Myeloperoxidase-induced biodegradation of singlewalled carbon nanotubes is mediated by hypochlorite. Russian Journal of Bioorganic Chemistry, 2011;37(4):453-463.

Wang JT, Fabbro C, Venturelli E, Ménard-Moyon C, Chaloin O, Da Ros T, Methven L, Nunes A, Sosabowski JK, Mather SJ, Robinson MK, Amadou J, Prato M, Bianco A10, Kostarelos K, Al-Jamal KT.The relationship between the diameter of chemically-functionalized multiwalled carbon nanotubes and their organ biodistribution profiles in vivo. Biomaterials, 2014;29(35):9517-28.

Wang M, Thanou M. Targeting nanoparticles to cancer. Pharmacol Res, 2010;62(2):90-99.

Wang L, Shi J, Zhang H, Li H, Gao Y, Wang Z, Wang H, Li L, Zhang C, Chen CZhenzhong Zhang Z, Zhang Y. Synergistic anticancer effect of RNAi and photothermal therapy mediated by functionalized single-walled carbon nanotubes. Biomaterials, 2013;34(1): 262-274.)
Wang Y, Wang C, Jia Y, Cheng X, Lin Q, Zhu M, Lu Y, Ding L, Weng Z, Wu, K. (2014). Oxygen-Carbon Nanotubes as a Chemotherapy Sensitizer for Paclitaxel in Breast Cancer Treatment. PloS one, 2014;9(8):104209.

Wick P, Manser P, Limbach LK, Dettlaff-Weglikowska U, Krumeich F, Roth S, Stark WJ, Bruinink A. The degree and kind of agglomeration affect carbon nanotube cytotoxicity. Toxicology Letters, 2007;168 (2): 121-131

Wu Y, Phillips JA, Liu H, Yang R, Tan W. Carbon Nanotubes Protect DNA Strands during Cellular Delivery. Acs Nano, 2008;2(10):2023-2028.

Wu W, Li R, Bian X, Zhu Z, Ding D, Li X, Jia Z, Jiang X, Hu Y. Covalently combining carbon nanotubes with anticancer agent: preparation and antitumor activity. Acs Nano, 2009; 3(9): 2740-2750.

Xiao K, Li Y, Luo J, Lee JS, Xiao W, Gonik AM, Agarwal RG, Lam KS. The effect of surface charge on in vivo biodistribution of PEGoligocholic acid based micellar nanoparticles. Biomaterials, 2011;32(13):3435-3446.

Xu S, Olenyuk BZ, Okamoto CT, Hamm-Alvarez SF. Targeting receptor-mediated endocytotic pathways with nanoparticles: rationale and advances, Adv. Drug Deliv. Rev. 2013;65:121-138

Yameen B, Choi WI, Vilos C, Swami A, Shi J, Omid C, Farokhzad OC. Insight into nanoparticle cellular uptake and intracellular targeting.Journal of Controlled Release, 2014;190: 485-499.

Zhang C, Chen W, Alvarez PJ. (2014). Manganese Peroxidase Degrades Pristine but Not Surface-Oxidized (Carboxylated) Single-Walled Carbon Nanotubes. Environmental science \& technology, 2014; 48(14) 7918-7923.

Zhao Y, Allen BL, Star A. Enzymatic Degradation of Multiwalled Carbon Nanotubes. The Journal of Physical Chemistry A, 2011;115(34):9536-44.

Zolnik BS, Sadrieh N. Regulatory perspective on the importance of ADME assessment of nanoscale material containing drugs. Adv Drug Deliv Rev. 2009;61(6):422-427.

\section{How to cite this article:}

Juan Fernando Pinillos-Madrid, Cecilia Gallardo. Carbon Nanotubes: a viable drug delivery platform for the treatment of cancer. J App Pharm Sci, 2015; 5 (09): 143-152. 